haemolysis) when used for ductal stones compared with its use for gall bladder stones. ${ }^{5}$ However, Takacs et $\mathrm{al}^{3}$ used MTBE in much lower concentrations and reported only mild toxic side effects.

Furthermore, there are two important caveats concerning the efficacy of topical dissolution therapy for bile duct stones. Firstly, infusion of any solvent into the bile duct may result in clearance of stones by its mechanical effect; stones are flushed from the bile duct into the duodenum. This is true especially for those cases in which a sphincterotomy has been performed. Stone clearance may therefore result from spontaneous migration of stones or mechanical effect of infusion of solvents, or both, instead of true chemical dissolution. Secondly, fragmentation of bile duct stones (as reported in $50 \%$ of patients treated by Takacs $e t a l^{3}$ ) may also result from frictional forces between stones and the nasobiliary catheter as reported after treatment of bile duct stones with biliary endoprostheses. ${ }^{6}$

We feel that the use of topical dissolution therapy for bile duct stones should be limited to expert centres and to those patients in whom endoscopy and surgery are unsuccessful or contraindicated and in whom longterm endoscopic stenting is considered inappropriate. ${ }^{7}$ In these selected cases the use of DMSO in combination with other solvents like MTBE may be considered.

J J G H M BERGMAN Department of Gastroenterology, University of Amsterdam, Meibergdreef 9 , 1105 AZ Amsterdam The Netherlands

1 Igimi $\mathrm{H}$, Asakawa $\mathrm{S}$, Kataoka A, Shimura $\mathrm{H}$. Clinical trials of DMSO on the cases with intrahepatic stones. Gastroenterology 1984; 88: A1666.

2 Patty I, Javor T, Past T, Deli J, Horvath L. New solubilizing mixture for pigment gallstones. Gastroenterology 1987; 93: 665-7.

3 Takacs T, Hajnal F, Nagy I, Montet JC, Lonovics J. Effective dissolution therapy of bile duct stones with a new multicomponent solvent. European fournal of Gastroenterology and Hepatology 1993; 35: 867-70.

4 Neoptolemos JP, Hall C, O'Connor HJ, Murray WR, Carr-Locke DL. Methyl tert butyl ether for treating bile duct stones: the British Experience. Br f Surg 1990; 77: 32-5.

5 Allen MJ, Borody TJ, Thistle JL. In vitro dissolution of cholesterol gallstones. Gastroenterology 1985; 89: 1097-103.

6 Goldberg M, Huck HV, Ruchim M. Clearance of choledocholithias with indwelling biliary stents. Am f Gastroenterol 1993; 88: 1530-5.

7 Bergman JGHM, Rauws EAJ, Tijssen JGP Tytgat GNJ, Huibregtse K. Biliary endoprostheses in elderly patients with endoscopically irretrievable common bile duct stones: report on 117 patients. Gastrointest Endosc (in press).

\section{Inflammatory bowel disease in married couples}

EDITOR,-We read with interest the article about inflammatory bowel disease in married couples by Comes et al (Gut 1994; 35: 1316-8). We have under our care a married couple who both developed Crohn's disease after marriage.

The female partner (now 32 years) presented in 1988, one year after her marriage, with abdominal pain and arthropathy and was found to have multiple small bowel strictures on a barium meal follow through. A duodenal biopsy confirmed Crohn's disease.

The male partner (now 48 years) was found to have sarcoidosis 24 years ago with a positive lung biopsy. He presented one year ago, five years after his marriage, with colitis of the sigmoid colon. Biopsy showed Crohn's disease with granulomas. Both patients are white. Their marriage is non-consanguineous. The female partner's aunt is also a known case of Crohn's disease. The couple are therefore similar to the cases described by Comes et al in that symptoms of Crohn's disease developed in both after marriage.

K SINGH
J H B SAUNDERS
R J E FOLEY
Bedford General Hospital,
Bedford

BOOK
REVIEWS

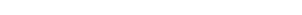

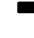

(1)

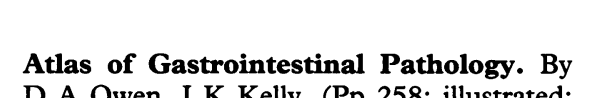
D A Owen, J K Kelly. (Pp 258; illustrated; £138.00.) Philadelphia: WB Saunders, 1994. ISBN 0721667309.

The product of two Canadian pathologists of considerable experience and standing in gastrointestinal pathology, this is an excellent synopsis of the subject. The text is organised in a standardised way, covering the whole of hollow organ alimentary pathology but not liver or pancreas, under the headings 'Biology of Disease', 'Clinical Features', 'Gross Pathology', 'Microscopic Pathology', 'Special Diagnostic Techniques', and 'Differential diagnosis'. The result is an admirably succinct review of gastrointestinal pathology, useful for both clinical gastroenterologists and pathologists. With the very comprehensive index and the clear style of the text, I am impressed with how easy it is to quickly find information that might be more difficult to locate elsewhere (for example, the distance of the landmarks in the oesophagus from the incisor teeth, or a brief biographical sketch about Harald Hirschsprung). There are important messages for clinical diagnosis and treatment. For example, with regard to tumours of the ampulla of Vater, the authors are quite right to state that 'superficial biopsies may reveal only an adenoma and miss the more deeply located malignancy. The presence of jaundice favors a diagnosis of malignancy'.

The reference lists at the end of each section are short and references are not cited in the text. The emphasis is on some of the classic papers rather than the more recent advances. The topics covered by the book are arranged into site specific chapters, with the exception of chapters on 'Diseases of Lymphoid Tissue', 'Stromal Lesions', and 'Neoplasms' and a further chapter entitled 'Diseases That May Affect Multiple Organs'. This includes graft $v$ host disease, eosinophilic gastroenteritis, ischaemia, vasculitis, Kaposi's sarcoma, etc. These are the least successful parts of the book. The section on lymphomas, particularly, is somewhat lacking in clarity.

Paradoxically, in a book, which calls itself an atlas, the weakest part is in the illustrations. Their small size and number and quality compare unfavourably with many extant standard textbooks with no pretensions to be atlases. The choice of topics illustrated is sometimes questionable. For example, six figures illustrate acute appendicitis, a condition surely familiar to every reader, while adenocarcinoma of the appendix and pseudomyxoma peritonei, much more difficult diagnostic problems, are each given only one figure, of indifferent quality. The illustrations of dysplasia in inflammatory bowel disease are inadequate.

Despite the last criticism, this is a beautifully organised quick reference source, particularly suitable for clinical gastroenterologists and pathologists in training, as well as experienced gastroenterologists who wish to see their patients in a clear light. I warmly recommend this book. Its high price means that it is more for departments to buy than for individuals to own.

I C TALBOT

Artificial Nutrition Support in Clinical Practice. Edited by J Payne-James, G Grimble, D Silk. (Pp 573; illustrated; £85.00.) London: Edward Arnold, 1994.

'It is intended that this volume may be read in its entirety or as individual chapters detailing specific subjects. We hope that any healthcare professional, who is developing an interest in clinical nutrition, will use the textbook as a sole source of information...'. So says the preface to this well produced, 37 chapter, 60 author book. Do gastroenterologists want or need this book? Can they not glean enough about nutritional support from the pages of Gut? Inspection of the index for the past three volumes of this journal suggest that they cannot. The entries for 'nutrition', 'nutritional support', 'parenteral nutrition', 'enteral nutrition', and 'enteral feeding' indicate some abstracts, but very few main articles on how and why to use artificial nutritional support in humans, although the development of techniques for nutritional support has been one of the important therapeutic advances in the past two decades. Moreover this is not a field in which the untutored amateur does well: instead he is very likely to kill patients and waste substantial amounts of money.

I would not advise anyone developing an interest in 'clinical nutrition' (here used as a synonym for 'artificial nutritional support') to start at the beginning of this book with a view to reading it straight through, if only because there are inevitably repetitious passages. For example methods for measuring energy expenditure are described on pp 43-47 ('Energy metabolism' by J Webber and I MacDonald), and then again on pp 138-141 ('Adult macronutrient requirements' by $\mathrm{H} \mathrm{P}$ Sauerwein and J A Romijn). The index is comprehensive and well cross referenced, however, so it is easy to find the topic on which you want to read. The place to start is chapter 7, by $\mathrm{S}$ Allison, on 'Malnutrition in hospital patients, and assessment of nutritional support'. Allison makes the vital distinction between malnutrition, which is an inevitable consequence of terminal disease, and malnutrition, which is an important and remediable component of the patient's illness. In the last case (but not the first) nutritional support may be very valuable. If the clinician who is a tyro as 'clinical nutrition' reads this chapter, and notes that some of his patients suffer from important and remediable malnutrition, then he should read the rest of the book, or else ensure that he can call on the services of a nutrition support team with the necessary expertise. 